\title{
Beyond the dinner table: who's having breakfast, lunch and dinner family meals and which meals are associated with better diet quality and BMI in pre-school children?
}

\author{
Jerica M Berge ${ }^{1, *}$, Kimberly P Truesdale ${ }^{2}$, Nancy E Sherwood ${ }^{3,4}$, Nathan Mitchell ${ }^{4}$, \\ William J Heerman ${ }^{5}$, Shari Barkin ${ }^{5}$, Donna Matheson ${ }^{6}$, Carolyn E Levers-Landis ${ }^{7}$ and \\ Simone A French ${ }^{4}$ \\ 'Department of Family Medicine and Community Health, University of Minnesota Medical School, Phillips \\ Wangensteen Building, 516 Delaware Street SE, Minneapolis, MN 55455, USA: ${ }^{2}$ Department of Nutrition, \\ University of North Carolina at Chapel Hill, Chapel Hill, NC, USA: ${ }^{3}$ HealthPartners Institute, Bloomington, MN, USA: \\ ${ }^{4}$ Division of Epidemiology and Community Health, University of Minnesota, Minneapolis, MN, USA: ${ }^{5}$ Division of \\ General Pediatrics, Vanderbilt University Medical Center, Nashville, TN, USA: ${ }^{6}$ Department of Pediatrics, Stanford \\ University, Stanford, CA, USA: ${ }^{7}$ Department of Pediatrics, University Hospitals Cleveland Medical Center and Case \\ Western Reserve University School of Medicine, Cleveland, OH, USA
}

Submitted 1 March 2017: Final revision received 20 July 2017: Accepted 24 July 2017: First published online 14 September 2017

\begin{abstract}
Objective: Having frequent family dinners is associated with better diet quality in children; however, it is unknown whether the frequency of certain family meal types (i.e. dinner) is more strongly associated with better child weight and diet quality compared with other meal types (i.e. breakfast, lunch). Thus, the current study examined the frequency of eating breakfast, lunch or dinner family meals and associations with pre-school children's overall diet quality (HEI-2010) and BMI percentile.

Design: Cross-sectional baseline data (2012-2014) from two randomized controlled childhood obesity prevention trials, NET-Works and GROW, were analysed together.

Setting: Studies were carried out in community and in-home settings in urban areas of Minnesota and Tennessee, USA.

Subjects: Parent-child (ages 2-5 years) pairs from Minnesota ( $n 222$ nonHispanics; $n 312$ Hispanics) and Tennessee ( $n 545$ Hispanics; $n 55$ non-Hispanics) participated in the study.

Results: Over $80 \%$ of families ate breakfast or lunch family meals at least once per week. Over $65 \%$ of families ate dinner family meals $\geq 5$ times/week. Frequency of breakfast family meals and total weekly family meals were significantly associated with healthier diet quality for non-Hispanic pre-school children $(P<0 \cdot 05)$, but not for Hispanic children. Family meal frequency by meal type was not associated with BMI percentile for non-Hispanic or Hispanic pre-school children.

Conclusions: Breakfast family meal frequency and total weekly family meal frequency were associated with healthier diet quality in non-Hispanic pre-school children but not in Hispanic children. Longitudinal research is needed to clarify the association between family meal type and child diet quality and BMI percentile.
\end{abstract}

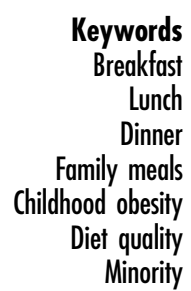

Prior research indicates that having frequent family meals is associated with positive health outcomes in children, including diets of higher nutritional quality and lower weight status ${ }^{(1-12)}$, although not all findings have been consistent $^{(13,14)}$. For example, several longitudinal studies and reviews of the literature have shown that having regular family meals (about 3-5 times/week) as a child is associated with higher intakes of fruits and vegetables,
Ca-rich foods, dietary fibre and key nutrients such as Ca and $\mathrm{Fe}$ as an adolescent or adult ${ }^{(4,8,9,15-20)}$. Additionally, cross-sectional and some longitudinal research has shown that having frequent family meals is associated with reduced risk of overweight/obesity in children and adolescents $^{(1,14,21)}$. While research suggests that family meals are protective for child diet quality and potentially weight status, little research has examined whether it matters if the 
family meal is breakfast, lunch or dinner ${ }^{(22,23)}$. It is important to understand whether one meal type conveys a more positive impact on child diet quality and weight status than another to inform research regarding which meals should be targeted in nutrition interventions. For example, if families are more likely to serve vegetables and fruits at dinner, then it may be important for interventions to target serving vegetables and fruits at family breakfast meals and/or lunches.

Additionally, little is known about the associations between eating breakfast, lunch or dinner together as a family and diet quality and weight status among children of pre-school age (i.e. 2-5 years old) and whether the relationship between eating breakfast, lunch or dinner family meals and diet quality and weight status is comparable to the positive association observed for older children (i.e. 6-12 years old) and adolescents (i.e. 13-18 years old ${ }^{(4,13,24)}$. Furthermore, previous research examining the protective influence of family meals on diet quality and weight status have not always included diverse samples. When race/ethnicity has been intentionally examined, results have been inconsistent. For example, several studies have shown that family dinner meals are protective for White ${ }^{(25)}$ and African-American youth ${ }^{(1,26)}$, but not for Hispanic youth ${ }^{(2,26,27)}$.

Thus, a first step in moving the field forward in understanding more about family meal type and associations with child diet quality would be to examine the types of family meals being eaten by pre-school children and their families and to examine whether the frequency of eating breakfast, lunch, dinner or total weekly family meals differs by sociodemographic characteristics and other household characteristics (i.e. family structure, working status, income, education). Additionally, it would be important to understand whether child overall diet quality and weight status are more strongly associated with one specific type of meal (i.e. breakfast, lunch, dinner) or the total number of family meals. Furthermore, examining whether one specific family meal type or the total number of family meals confers greater health behaviour benefits for different racial/ethnic groups would also be important.

Examining associations between the frequency of eating breakfast, lunch or dinner family meals and child diet quality and weight status may also be important for informing the design of public health messages and interventions to promote particular family meals. For example, if results show that eating breakfast, lunch or dinner family meals to be equally associated with higher diet quality and lower weight status in pre-school children, then public health messages could inform parents that eating any meal together as a family may be beneficial for child weight and weight-related behaviours. Such messages would have the potential to reduce barriers to eating family meals and increase the likelihood that more families would benefit from the protective nature of family meals.
There are two aims of the current study: (i) to describe the frequency of eating breakfast, lunch, dinner and total weekly family meals among Hispanic and non-Hispanic pre-school children aged 2-5 years, including differences according to sociodemographic and other household characteristics; and (ii) to examine the association of the frequency of eating breakfast, lunch, dinner and total weekly family meals with child diet quality and BMI percentile among Hispanic and non-Hispanic pre-school children. The main hypothesis is that the frequency of eating all types of family meals (i.e. breakfast, lunch, dinner) will be associated with similar benefits for healthier weight and higher diet quality in pre-school children.

\section{Methods}

\section{Study design and population}

The present study uses baseline data from the NETWorks $^{(28)}$ (Now Everybody Together for Amazing and Healthy Kids) and GROW ${ }^{(29)}$ (Growing Right Onto Wellness) studies. These two studies are 3-year randomized childhood obesity prevention trials, which are a part of the National Institutes of Health's (NIH) Childhood Obesity Prevention and Treatment Research (COPTR) Consortium (intervention years 2013-2017). Both sites included samples with over $50 \%$ Hispanic households and the majority of families earning less than \$US 50000 per year, which allows for examining associations between family meal type and diet quality and weight status in minority and low-income populations

\section{NET-Works study}

In 2012-2014 the NET-Works study (clinical trial registration number NCT01606891) recruited and randomized 534 pre-school children who were 2-4 years old, above the 50th percentile for age- and sex-adjusted height and weight (as measured by the Centers for Disease Control and Prevention standardized growth charts $\left.{ }^{(30)}\right)$ and from low-income households (< \$US 65000 annual household income) in the Minneapolis and St. Paul area, Minnesota, $\mathrm{USA}^{(28)}$. The NET-Works intervention integrates and links resources across home, community, primary-care clinics and neighbourhoods to promote healthy eating and activity patterns and body weight among lower-income, racially/ethnically diverse pre-school children.

\section{GROW study}

In 2012-2014 the GROW study (clinical trial registration number NCT01316653) ${ }^{(29)}$ randomized 610 parent-preschool child (ages 3-5 years) pairs from underserved, low-income communities in Nashville, Tennessee, USA. Eligible children were between the 50th and 95th percentile for age- and sex-adjusted height and weight (as measured by the Centers for Disease Control and Prevention standardized growth charts $\left.{ }^{(30)}\right)$. Additionally, 
potential participants were eligible for GROW if they received at least one form of government assistance, spoke English or Spanish, the parent was over 18 years old, and both parent and child could participate in physical activity. The GROW intervention is a staged-intensity behavioural intervention. Throughout the intervention parents and children build skills in nutrition, physical activity and parenting, with a concurrent focus on forming new social networks and utilizing the built environment of parks and recreation for family health.

Complete details about the NET-Works ${ }^{(28)}$ and $\mathrm{GROW}^{(29)}$ study designs, full inclusion/exclusion criteria, intervention and evaluation are published elsewhere ${ }^{(28,29)}$. The Institutional Review Board (IRB) Human Subjects Committee at the University of Minnesota and Vanderbilt University approved all protocols used in NET-Works and GROW study, respectively. All participants signed written informed consent prior to participation into the respective studies. Additionally, the University of North Carolina at Chapel Hill IRB, which is the coordinating centre for the COPTR Consortium, approved the analysis of the data from both studies.

\section{Measures}

Standardized objective measures, including three $24 \mathrm{~h}$ dietary recalls, anthropometry and parent self-report surveys, were conducted by trained and certified research staff from the NET-Works and GROW studies in participants' homes or local community centres. All surveys were administered in English or Spanish according to participant preference and completed by the index parent/guardian prior to randomization.

\section{Exposure variables: family meals}

Questions assessing the frequency of breakfast ( $\mathrm{el}$ desayuno), lunch (el almuerzo), dinner (la cena) and total weekly family meals were taken from previously validated surveys ${ }^{(8,13,31)}$. Frequency of breakfast, lunch and dinner family meals was measured at baseline. The primary caregiver/guardian was asked three questions about family meals. For the NET-Works study, primary caregivers were asked: 'During the past seven days, how often did your family eat breakfast (lunch, dinner) together?' (response options: 0, 1-2, 3-4, 5-6 or 7 times). GROW study primary caregivers were asked: 'During the past seven days, how often did most of your family eat breakfast (lunch, dinner) together?' (response options: 0, 1-2, 3-4, 5-6 or 7 times). Thus, the family meal frequency questions were asked slightly differently at each site. A pseudo-continuous variable was created for analyses by coding the categorical response options as $0,1 \cdot 5,3 \cdot 5,5 \cdot 5$ and 7 , respectively, for each of the questions about breakfast, lunch and dinner family meals. The total weekly family meals variable was the sum of the variables for breakfast, lunch and dinner.

\section{Outcome variables}

Child height and weight

Child height and weight were measured with the participant in light clothing without shoes. Body weight was measured to the nearest $0 \cdot 1 \mathrm{~kg}$ using a calibrated electronic scale (Seca Corp., Chino, CA, USA). Height was measured to the nearest $0.1 \mathrm{~cm}$ using a portable stadiometer (Seca Corp.). Measures were conducted in duplicate and averaged. BMI was calculated as weight in kilograms divided by the square of height in metres and transformed to age- and sex-specific percentiles based on Centers for Disease Control and Prevention guidelines ${ }^{(32)}$.

\section{Child dietary quality}

In both studies, child dietary quality was assessed using the Nutrition Data Software for Research (NDS-R) version 2010 (Nutrition Coordinating Center, University of Minnesota, Minneapolis, MN, USA). Three $24 \mathrm{~h}$ dietary recalls were pre-scheduled with the parent and administered by telephone in English or Spanish. The primary caregiver or guardian served as proxy for the child to report the child's previous day intake. Booklets showing food amounts were used by the respondent to assist in identifying portion sizes. For children in childcare, food records were given to the childcare provider and the completed form was used by the parent to report foods the child consumed while in childcare. Diet recalls were conducted on weekdays and weekend days with a maximum of three recalls (two weekdays and one weekend day) and a minimum of two dietary recalls. Total energy, nutrients and food groups from the two or three dietary recalls were averaged to estimate the child's typical diet quality.

Dietary quality was computed using the 2010 Healthy Eating Index (HEI-2010) ${ }^{(33,34)}$. The HEI-2010 includes nine adequacy components (total fruit, whole fruit, total vegetables, greens and beans, whole grains, dairy, total protein foods, seafood and plant proteins, fatty acids) and three moderation components (refined grains, sodium, empty calories). Participants received a score for the twelve components and the component scores were summed to create the total HEI-2010 score. For the adequacy components, a higher score indicates higher consumption and for the moderation components, a higher score indicates lower consumption. The total HEI-2010 score's upper range is 100 , with higher scores indicating better child diet quality.

\section{Covariates}

All demographic covariates were chosen because of prior research showing they are confounders of the relationship between the exposure and outcome variables in the study $^{(1,3,35)}$.

\section{Demographic variables}

Children were categorized as Hispanic or non-Hispanic for the analysis based on parent report. The primary parent/ guardian also reported the age (date of birth) and sex of the 
child and his/her own marital status (married/living as married, single), employment status (full-time, part-time, not working for pay) and country of birth (born in USA; yes, no). Household education was calculated using the highest level of education reported from the following two sources: the index parent's self-reported education level and the highest education of other adults in household ( $<$ high school, high school or equivalent, at least some college). Annual household income (<\$US 14999, \$US 15000-24999, \$US 2500034999, \$US 35000-79999, don't know, no response) and household-level participation in the Supplemental Nutrition Assistance Program (SNAP) and Special Supplemental Nutrition Program for Women, Infants, and Children (WIC) were self-reported by the primary caregiver.

\section{Statistical analysis}

Data from the NET-Works and GROW studies were combined and all analyses were pre-stratified by Hispanic origin a priori, based on previous studies showing differential benefits of family meals for non-Hispanic $v$. Hispanic populations ${ }^{(2,26,27)}$. Eleven participants from the GROW study were excluded from analyses based on the following reasons: having fewer than two dietary recalls ( $n$ 1 ), missing one or more family meals questions ( $n$ 3) or having a BMI percentile outside the range (i.e. <50th percentile or $>95$ th percentile; $n 7$ ). The final analysis sample was 276 non-Hispanics and 857 Hispanics. Unadjusted mean numbers of breakfast, lunch, dinner and total weekly family meals were compared across sociodemographic characteristics using linear regression (PROC GENMOD with linear distribution and LSMEANS option). Bonferroni corrections were made to account for the multiple comparisons. The corrected level of statistical significance was $P<0.00143$ for non-Hispanics and $P<0.00161$ for Hispanics.

The associations between breakfast, lunch, dinner and total weekly family meals and the HEI-2010 and BMI percentile using linear regression (PROC GENMOD with linear distribution) was examined. For each meal type, three models were run. Model 1 was unadjusted and Model 2 adjusted for age, sex, marital status, employment status and study site. Model 3 adjusted for all the covariates in Model 2 plus the number of times the other two family meals were eaten together, to try and distinguish each meal's effect from the total number of meals consumed together. We also adjusted for race/ethnicity in Models 2 and 3 for the non-Hispanics. When the outcome of interest was BMI percentile, we included mean total daily energy intake in the adjusted regression models. Data were analysed using the statistical software package SAS version 9.3 (2016).

\section{Results}

The mean age of children in the sample was 3.5 (SD 0.9) years for non-Hispanic children and 4.0 (SD 0.9) for Hispanic children. About $49 \%$ of the children were male
(Table 1). By design of the studies, about half of the children were in the upper range of the normal weight category as defined by BMI percentile and half were in the overweight/obese range. The mean age of parent participants was 31.5 (SD 6.8) years for non-Hispanic parents and 31.9 (SD 6.0) years for Hispanic parents. Most parents were overweight or obese. Average household income was <\$US 35000 per year and over $50 \%$ of Hispanic participants had less than a high school education, while over $70 \%$ of non-Hispanic participants had at least some college education.

\section{Frequency of eating breakfast, lunch, dinner and total weekly family meals}

Overall, non-Hispanic and Hispanic households had similar frequency patterns of eating breakfast, lunch, dinner and total weekly family meals (Fig. 1).

\section{Breakfast}

Breakfast family meal patterns (Fig. 1(a)) were similar for non-Hispanic and Hispanic households, with the majority of families eating breakfast family meals between one and four times weekly. About $20 \%$ of all children ate five or more breakfast family meals per week.

\section{Lunch}

Lunch family meal patterns (Fig. 1(b)) were similar for non-Hispanic and Hispanic households, with the majority of families eating between one and four lunch family meals per week. About $20 \%$ of all children ate five or more lunch family meals weekly.

\section{Dinner}

Dinner family meal patterns (Fig. 1(c)) were similar for non-Hispanic and Hispanic households, with almost $90 \%$ of families eating three or more family dinner meals per week. About $50 \%$ of all pre-school children ate seven family dinner meals weekly.

\section{Total meals}

The majority of non-Hispanic and Hispanic households ate between five and sixteen meals per week (Fig. 1(d)). A larger percentage of Hispanic households (15\%) ate all family meals (twenty-one meals in total) together compared with $6 \%$ of non-Hispanic households.

\section{Differences in the frequency of baving breakfast, lunch and dinner family meals by sociodemographic characteristics}

There were some significant differences in family meal frequency by sociodemographic characteristics (Table 2). Non-Hispanic White children on average had significantly more breakfast family meals compared with non-Hispanic Black children and non-Hispanic multiracial children. In addition, non-Hispanic normal-weight parents on average had significantly more breakfast family meals compared with non-Hispanic parents who were obese. Additionally, 
Table 1 Mean and frequency distribution of sociodemographic characteristics for non-Hispanic and Hispanic households; baseline data from NET-Works and GROW studies among parent-child (aged 2-5 years) pairs from respectively Minnesota ( $n 222$ non-Hispanics; $n 312$ Hispanics) and Tennessee ( $n 545$ Hispanics; $n 55$ non-Hispanics), USA, 2012-2014

\begin{tabular}{|c|c|c|c|c|}
\hline & \multicolumn{2}{|c|}{$\begin{array}{l}\text { Non-Hispanic households } \\
\text { ( }(n 276)\end{array}$} & \multicolumn{2}{|c|}{$\begin{array}{l}\text { Hispanic households } \\
\text { ( } n \text { 857) }\end{array}$} \\
\hline & Mean & SD & Mean & SD \\
\hline Child age (years) & 3.5 & 0.9 & 4.0 & 0.9 \\
\hline Sex (\% boys) & \multicolumn{2}{|c|}{$47 \cdot 1$} & \multicolumn{2}{|c|}{$49 \cdot 1$} \\
\hline \multicolumn{5}{|l|}{ Child race/ethnicity (\%) } \\
\hline White & \multicolumn{2}{|c|}{$26 \cdot 4$} & \multicolumn{2}{|c|}{ - } \\
\hline Black & \multicolumn{2}{|c|}{$48 \cdot 2$} & \multicolumn{2}{|c|}{-} \\
\hline Multiracial & \multirow{2}{*}{\multicolumn{2}{|c|}{$\begin{array}{r}18.5 \\
6.9\end{array}$}} & \multicolumn{2}{|c|}{-} \\
\hline Other & & & \multicolumn{2}{|c|}{-} \\
\hline Child BMI percentile & $79 \cdot 8$ & $14 \cdot 0$ & $79 \cdot 1$ & $13 \cdot 6$ \\
\hline \multicolumn{5}{|l|}{ BMI percentile categories } \\
\hline 50th-84.9th & \multicolumn{2}{|c|}{$56 \cdot 9$} & \multicolumn{2}{|c|}{59.9} \\
\hline 85th-94.9th & \multicolumn{2}{|c|}{$27 \cdot 9$} & \multicolumn{2}{|c|}{30.9} \\
\hline$\geq 95$ th & \multicolumn{2}{|c|}{$15 \cdot 2$} & \multicolumn{2}{|c|}{9.2} \\
\hline Parent age (years) & 31.5 & $6 \cdot 8$ & 31.9 & $6 \cdot 0$ \\
\hline Parent BMI $\left(\mathrm{kg} / \mathrm{m}^{2}\right)$ & 31.0 & 8.6 & 29.5 & $5 \cdot 5$ \\
\hline Parent marital status ( $\%$ married or living as married) & \multicolumn{2}{|c|}{$54 \cdot 4$} & \multicolumn{2}{|c|}{83.4} \\
\hline Household education (\%) & \multirow{2}{*}{\multicolumn{2}{|c|}{$9 \cdot 8$}} & \multirow{2}{*}{\multicolumn{2}{|c|}{$54 \cdot 0$}} \\
\hline$<$ High school & & & & \\
\hline High school or equivalent & \multicolumn{2}{|c|}{$19 \cdot 6$} & \multicolumn{2}{|c|}{$25 \cdot 5$} \\
\hline At least some college & \multicolumn{2}{|c|}{70.6} & \multicolumn{2}{|c|}{$20 \cdot 4$} \\
\hline \multicolumn{5}{|l|}{ Income (\%) } \\
\hline$<$ SUS 14999 & \multicolumn{2}{|c|}{33.0} & & \\
\hline \$US $15000-24999$ & & & & \\
\hline \$US $25000-34999$ & & & & \\
\hline \$US $35000-79999$ & & & & \\
\hline Don't know or didn't respond & & & & \\
\hline Parent job status (\%) & & & & \\
\hline Full-time & & & & \\
\hline Part-time & & & & \\
\hline Not working for pay & & & & \\
\hline Parent born in USA (\% yes) & & & & \\
\hline HEl-2010 total score & 59.9 & 12.5 & 65.5 & $10 \cdot 8$ \\
\hline
\end{tabular}

NET-Works, Now Everybody Together for Amazing and Healthy Kids; GROW, Growing Right Onto Wellness; SNAP, Supplemental Nutrition Assistance Program; WIC, Special Supplemental Nutrition Program for Women, Infants, and Children; HEI-2010, Health Eating Index-2010.

younger Hispanic children on average had more breakfast, lunch and total family meals compared with older Hispanic children. For both non-Hispanic and Hispanic pre-school children, there was a higher frequency of eating breakfast, lunch, dinner and total weekly family meals when children were from households where a parent was either not working for pay or working parttime compared with children from households where a parent was working full-time.

\section{Associations between breakfast, lunch and dinner family meals and pre-school children's Healthy Eating Index-2010 score and BMI percentile}

Breakfast family meals

There was a statistically significant positive association between eating breakfast family meals and diet quality as measured by HEI-2010 in non-Hispanic pre-school children compared with Hispanic pre-school children in all models $(P<0.05$; Table 3$)$. For example, for every one-day increase in eating breakfast family meals, non-Hispanic pre-school children's HEI-2010 scores were higher by 1.30, after adjusting for sociodemographic characteristics and lunch and dinner family meals. There were no significant findings for breakfast family meal frequency and weight status for non-Hispanic or Hispanic pre-school children.

\section{Lunch and dinner family meals}

There were no significant findings for lunch or dinner family meals and HEI-2010 or weight status for nonHispanic or Hispanic pre-school children (Table 3).

\section{Total meals}

There was a significant positive association between the total number of family meals eaten per week and HEI-2010 scores in non-Hispanic pre-school children compared with Hispanic pre-school children in all models $(P<0 \cdot 05$; Table 3$)$. There were no significant associations between the total number of family meals per week and weight status for non-Hispanic or Hispanic pre-school children (Table 3). 
(a)

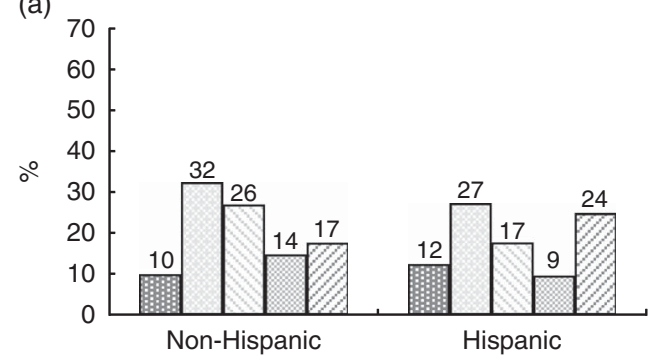

(b)

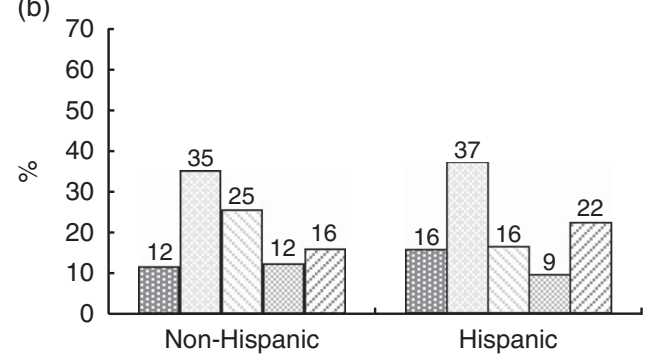

(c)

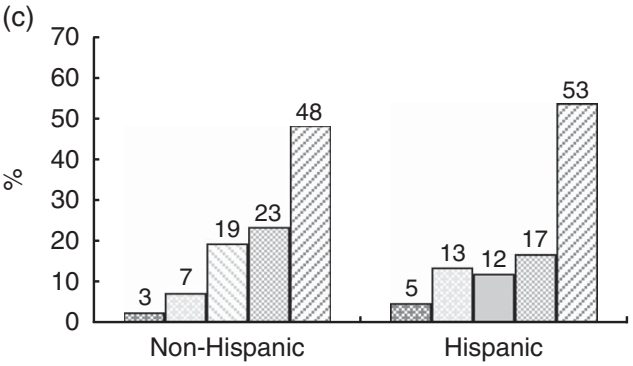

(d)

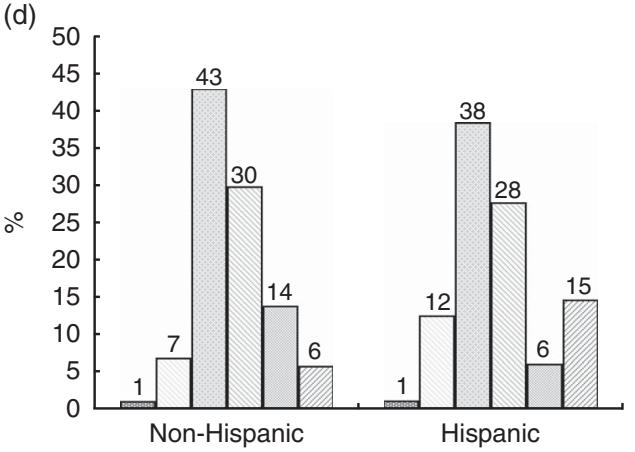

Fig. 1 Distribution of eating breakfast (a), lunch (b), dinner (c) and total family meals (d) among non-Hispanic and Hispanic households; baseline data from NET-Works and GROW studies among parent-child (aged 2-5 years) pairs from respectively Minnesota (n 222 non-Hispanics; n 312 Hispanics) and Tennessee (n 545 Hispanics; $n 55$ non-Hispanics), USA, 2012-2014. Frequency of eating breakfast family meals, lunch family meals and dinner family meals: 笅, never; $\ulcorner, 1-2$ times/ week; $\sqsubset$, 3-4 times/week; $\square, 5-6$ times/week; $\mathbb{Z}, 7$ times/week. Frequency of eating total family meals: 橉, never; $\square, 1$ to $<5$ times/ week; $\square, 5$ to $<11$ times/week; $\sqsubset, 11$ to $<17$ times/week; $\square, 17$ to $<21$ times/week; $\mathbb{Z}, 21$ times/week (NET-Works, Now Everybody Together for Amazing and Healthy Kids; GROW, Growing Right Onto Wellness)

The online supplementary material, Supplemental Table 1, shows associations between family meal types (breakfast, lunch, dinner, total meals) and diet quality scores for each of the twelve HEI-2010 components among non-Hispanic and Hispanic pre-school children. As can be seen, specific components (e.g. fruit, vegetables, greens and beans, seafood and plant proteins) consistently contributed to the finding that breakfast and overall total family meals are beneficial for the diet quality of nonHispanic pre-school children but not for Hispanics.

\section{Discussion}

The present results indicated that most children of preschool age ate breakfast and lunch family meals at least once or twice per week and more than half of children ate dinner family meals five or more times per week. Limited prior research has examined breakfast, lunch and dinner family meal patterns ${ }^{(3,13)}$ in pre-school children; thus, these new findings add to the pre-existing literature on family meals and suggest that it is fairly common for families with pre-school children to eat breakfast and lunch family meals ${ }^{(3)}$. Additionally, family dinner meal frequency results in the current study are consistent with previous studies among older children showing that it is common for families to eat at least five family dinner meals or more per week ${ }^{(2,4,18,36)}$.

There were some significant differences in the frequency of eating family meals within meal type by sociodemographic characteristics. For example, in households where a parent worked part-time or did not work for pay, pre-school children ate more breakfast, lunch, dinner and total family meals compared with pre-school children who had a parent who worked full-time. This may mean that family meals are more challenging/logistically problematic (e.g. time constraints) to carry out for families where the primary caregiver works full-time.

Results indicated that frequency of breakfast family meals per week and total weekly family meals (any type breakfast, lunch, dinner) were significantly associated with non-Hispanic pre-school children's diet quality, but these associations were not evident for Hispanic pre-school children. This result corroborates prior research showing that the frequency of breakfast family meals and total weekly family meals are positively associated with better diet quality for children of elementary-school age and adolescents $^{(1-4,10,13,37)}$ and extends previous studies by showing that pre-school children receive dietary benefits from breakfast family meals too. This result is also consistent with previous literature showing that associations between family meals and diet quality are more likely to be observed among non-Hispanic children compared with Hispanic children ${ }^{(2,26,27)}$. One potential reason why only breakfast and total family meals were significantly associated with pre-school children's diet quality may be because the frequency of having family dinner meals was already high. Additionally, one potential reason why significant results were not found for Hispanic children 
Table 2 Unadjusted mean number of breakfast, lunch and dinner family meals per week among non-Hispanic and Hispanic households; baseline data from NET-Works and GROW studies among parent-child (aged 2-5 years) pairs from respectively Minnesota ( $n 222$ nonHispanics; $n 312$ Hispanics) and Tennessee ( $n 545$ Hispanics; $n 55$ non-Hispanics), USA, 2012-2014

\begin{tabular}{|c|c|c|c|c|c|c|c|c|c|c|c|c|c|c|c|c|}
\hline & \multicolumn{8}{|c|}{ Non-Hispanic households ( $n$ 276) } & \multicolumn{8}{|c|}{ Hispanic households ( $n$ 857) } \\
\hline & \multicolumn{2}{|c|}{ Breakfast } & \multicolumn{2}{|c|}{ Lunch } & \multicolumn{2}{|c|}{ Dinner } & \multicolumn{2}{|c|}{ Total } & \multicolumn{2}{|c|}{ Breakfast } & \multicolumn{2}{|c|}{ Lunch } & \multicolumn{2}{|c|}{ Dinner } & \multicolumn{2}{|c|}{ Total } \\
\hline & Mean & SD & Mean & SD & Mean & SD & Mean & SD & Mean & SD & Mean & SD & Mean & SD & Mean & SD \\
\hline $\begin{array}{l}\text { Overall family meal frequency } \\
\text { Child age (years) }\end{array}$ & $3 \cdot 4$ & $2 \cdot 3$ & $3 \cdot 2$ & $2 \cdot 3$ & $5 \cdot 4$ & 1.9 & $12 \cdot 0$ & 4.9 & 3.4 & $2 \cdot 5$ & $3 \cdot 2$ & $2 \cdot 5$ & $5 \cdot 3$ & $2 \cdot 3$ & $11 \cdot 8$ & $5 \cdot 7$ \\
\hline $\begin{array}{l}2 \\
3 \\
4 \\
5\end{array}$ & $\begin{array}{l}3 \cdot 7 \\
3 \cdot 5 \\
3 \cdot 4 \\
1 \cdot 7\end{array}$ & $\begin{array}{l}0.3 \\
0.2 \\
0.2 \\
0.6\end{array}$ & $\begin{array}{l}3 \cdot 5 \\
3 \cdot 3 \\
3 \cdot 0 \\
1 \cdot 4\end{array}$ & $\begin{array}{l}0.3 \\
0.2 \\
0.2 \\
0.6\end{array}$ & $\begin{array}{l}4 \cdot 9 \\
5 \cdot 5 \\
5 \cdot 6 \\
6 \cdot 0\end{array}$ & $\begin{array}{l}0.2 \\
0.2 \\
0.2 \\
0.6\end{array}$ & $\begin{array}{r}12 \cdot 1 \\
12 \cdot 3 \\
12 \cdot 0 \\
9 \cdot 1\end{array}$ & $\begin{array}{l}0.6 \\
0.5 \\
0.5 \\
1.4\end{array}$ & $\begin{array}{l}4 \cdot 2 \\
3 \cdot 4 \\
3 \cdot 4 \\
3 \cdot 0\end{array}$ & $\begin{array}{l}0.3 \\
0.1 \\
0.2 \\
0.2\end{array}$ & $\begin{array}{l}3 \cdot 9 \\
3 \cdot 2 \\
3 \cdot 2 \\
2 \cdot 6\end{array}$ & $\begin{array}{l}0.3 \\
0.1 \\
0.2 \\
0.2\end{array}$ & $\begin{array}{l}5 \cdot 1 \\
5 \cdot 2 \\
5 \cdot 5 \\
5 \cdot 1\end{array}$ & $\begin{array}{l}0.3 \\
0.1 \\
0.2 \\
0.2\end{array}$ & $\begin{array}{l}13 \cdot 2 \\
11 \cdot 8 \\
12 \cdot 2 \\
10 \cdot 6\end{array}$ & $\begin{array}{l}0.6 \\
0.3 \\
0.4 \\
0.5\end{array}$ \\
\hline Sex & & & & & & & & & & & & & & & & \\
\hline $\begin{array}{l}\text { Boys } \\
\text { Girls }\end{array}$ & $\begin{array}{l}3 \cdot 4 \\
3 \cdot 4\end{array}$ & $\begin{array}{l}0.2 \\
0.2\end{array}$ & $\begin{array}{l}3 \cdot 1 \\
3 \cdot 3\end{array}$ & $\begin{array}{l}0.2 \\
0.2\end{array}$ & $\begin{array}{l}5 \cdot 4 \\
5 \cdot 4\end{array}$ & $\begin{array}{l}0.2 \\
0.2\end{array}$ & $\begin{array}{l}11 \cdot 9 \\
12 \cdot 1\end{array}$ & $\begin{array}{l}0.4 \\
0.4\end{array}$ & $\begin{array}{l}3 \cdot 3 \\
3 \cdot 4\end{array}$ & $\begin{array}{l}0.1 \\
0.1\end{array}$ & $\begin{array}{l}3 \cdot 1 \\
3 \cdot 2\end{array}$ & $\begin{array}{l}0 \cdot 1 \\
0 \cdot 1\end{array}$ & $\begin{array}{l}5 \cdot 2 \\
5 \cdot 4\end{array}$ & $\begin{array}{l}0.1 \\
0.1\end{array}$ & $\begin{array}{l}11 \cdot 6 \\
12 \cdot 0\end{array}$ & $\begin{array}{l}0.3 \\
0.3\end{array}$ \\
\hline Child race/ethnicity & & & & & & & & & & & & & & & & \\
\hline $\begin{array}{l}\text { White } \\
\text { Black } \\
\text { Multiracial } \\
\text { Other }\end{array}$ & $\begin{array}{l}4 \cdot 5 \\
3 \cdot 0 \\
3 \cdot 0 \\
2 \cdot 8\end{array}$ & $\begin{array}{l}0.3 \\
0.2 \\
0.3 \\
0.5\end{array}$ & $\begin{array}{l}4 \cdot 0 \\
2 \cdot 9 \\
2 \cdot 9 \\
3 \cdot 0\end{array}$ & $\begin{array}{l}0.3 \\
0.2 \\
0.3 \\
0.5\end{array}$ & $\begin{array}{l}5 \cdot 5 \\
5 \cdot 3 \\
5 \cdot 6 \\
5 \cdot 2\end{array}$ & $\begin{array}{l}0.2 \\
0.2 \\
0.3 \\
0.4\end{array}$ & $\begin{array}{l}14 \cdot 0 \\
11.2 \\
11.5 \\
11.0\end{array}$ & $\begin{array}{l}0.6 \\
0.4 \\
0.7 \\
1.1\end{array}$ & $\begin{array}{l}- \\
- \\
- \\
-\end{array}$ & $\begin{array}{l}- \\
- \\
- \\
-\end{array}$ & $\begin{array}{l}- \\
- \\
- \\
-\end{array}$ & $\begin{array}{l}- \\
- \\
- \\
-\end{array}$ & $\begin{array}{l}- \\
- \\
- \\
-\end{array}$ & $\begin{array}{l}- \\
- \\
- \\
-\end{array}$ & $\begin{array}{l}- \\
- \\
- \\
-\end{array}$ & $\begin{array}{l}- \\
- \\
- \\
-\end{array}$ \\
\hline BMI percentile categories & & & & & & & & & & & & & & & & \\
\hline $\begin{array}{l}\text { 50th-84.9th } \\
\text { 85th-94.9th } \\
\text { >95th }\end{array}$ & $\begin{array}{l}3 \cdot 4 \\
3 \cdot 5 \\
3 \cdot 3\end{array}$ & $\begin{array}{l}0.2 \\
0.3 \\
0.4\end{array}$ & $\begin{array}{l}3 \cdot 3 \\
2 \cdot 9 \\
3 \cdot 5\end{array}$ & $\begin{array}{l}0.2 \\
0.3 \\
0.3\end{array}$ & $\begin{array}{l}5 \cdot 3 \\
5 \cdot 7 \\
5 \cdot 1\end{array}$ & $\begin{array}{l}0.2 \\
0.2 \\
0.3\end{array}$ & $\begin{array}{l}12 \cdot 0 \\
12 \cdot 1 \\
11 \cdot 9\end{array}$ & $\begin{array}{l}0.4 \\
0.6 \\
0.8\end{array}$ & $\begin{array}{l}3 \cdot 4 \\
3 \cdot 3 \\
3 \cdot 4\end{array}$ & $\begin{array}{l}0.1 \\
0.2 \\
0.3\end{array}$ & $\begin{array}{l}3 \cdot 2 \\
3 \cdot 2 \\
3 \cdot 3\end{array}$ & $\begin{array}{l}0.1 \\
0.2 \\
0.3\end{array}$ & $\begin{array}{l}5 \cdot 2 \\
5 \cdot 4 \\
5 \cdot 0\end{array}$ & $\begin{array}{l}0 \cdot 1 \\
0 \cdot 1 \\
0.3\end{array}$ & $\begin{array}{l}11.8 \\
11.9 \\
11.7\end{array}$ & $\begin{array}{l}0.3 \\
0.3 \\
0.6\end{array}$ \\
\hline Adult BMI categories & & & & & & & & & & & & & & & & \\
\hline $\begin{array}{l}\text { Underweight } \\
\text { Normal weight } \\
\text { Overweight } \\
\text { Obese }\end{array}$ & $\begin{array}{l}4 \cdot 0 \\
4 \cdot 1 \\
3 \cdot 6 \\
3 \cdot 0\end{array}$ & $\begin{array}{l}1.3 \\
0.3 \\
0.3 \\
0.2\end{array}$ & $\begin{array}{l}4 \cdot 2 \\
3 \cdot 5 \\
3.5 \\
3 \cdot 0\end{array}$ & $\begin{array}{l}1 \cdot 3 \\
0.3 \\
0.3 \\
0.2\end{array}$ & $\begin{array}{l}5 \cdot 8 \\
5 \cdot 2 \\
5 \cdot 7 \\
5 \cdot 4\end{array}$ & $\begin{array}{l}1 \cdot 1 \\
0.2 \\
0.2 \\
0.2\end{array}$ & $\begin{array}{l}14 \cdot 0 \\
12 \cdot 8 \\
12 \cdot 8 \\
11.3\end{array}$ & $\begin{array}{l}2.8 \\
0.6 \\
0.6 \\
0.4\end{array}$ & $\begin{array}{l}3.5 \\
3.4 \\
3.2 \\
3.5\end{array}$ & $\begin{array}{l}1.3 \\
0.2 \\
0.1 \\
0.1\end{array}$ & $\begin{array}{l}2 \cdot 6 \\
3 \cdot 1 \\
3 \cdot 1 \\
3 \cdot 3\end{array}$ & $\begin{array}{l}1.3 \\
0.2 \\
0.1 \\
0.1\end{array}$ & $\begin{array}{l}5 \cdot 8 \\
5 \cdot 3 \\
5 \cdot 2 \\
5 \cdot 3\end{array}$ & $\begin{array}{l}1 \cdot 1 \\
0.2 \\
0 \cdot 1 \\
0.1\end{array}$ & $\begin{array}{l}11.9 \\
11.7 \\
11.5 \\
12.1\end{array}$ & $\begin{array}{l}2.8 \\
0.4 \\
0.3 \\
0.3\end{array}$ \\
\hline Marital status & & & & & & & & & & & & & & & & \\
\hline $\begin{array}{l}\text { Married or living as married } \\
\text { Single }\end{array}$ & $\begin{array}{l}3 \cdot 6 \\
3 \cdot 2\end{array}$ & $\begin{array}{l}0.2 \\
0.2\end{array}$ & $\begin{array}{l}3.4 \\
2.9\end{array}$ & $\begin{array}{l}0.2 \\
0.2\end{array}$ & $\begin{array}{l}5 \cdot 5 \\
5 \cdot 3\end{array}$ & $\begin{array}{l}0.2 \\
0.2\end{array}$ & $\begin{array}{l}12 \cdot 5 \\
11.5\end{array}$ & $\begin{array}{l}0.4 \\
0.4\end{array}$ & $\begin{array}{l}3 \cdot 4 \\
3 \cdot 3\end{array}$ & $\begin{array}{l}0.1 \\
0.2\end{array}$ & $\begin{array}{l}3 \cdot 2 \\
2 \cdot 8\end{array}$ & $\begin{array}{l}0.1 \\
0.2\end{array}$ & $\begin{array}{l}5 \cdot 3 \\
5 \cdot 3\end{array}$ & $\begin{array}{l}0 \cdot 1 \\
0 \cdot 2\end{array}$ & $\begin{array}{l}11.9 \\
11.5\end{array}$ & $\begin{array}{l}0.2 \\
0.5\end{array}$ \\
\hline Household education & & & & & & & & & & & & & & & & \\
\hline $\begin{array}{l}<\text { High school } \\
\text { High school or equivalent } \\
\text { At least some college }\end{array}$ & $\begin{array}{l}2 \cdot 9 \\
3 \cdot 5 \\
3 \cdot 5\end{array}$ & $\begin{array}{l}0.4 \\
0.3 \\
0.2\end{array}$ & $\begin{array}{l}3.7 \\
3.0 \\
3.2\end{array}$ & $\begin{array}{l}0.4 \\
0.3 \\
0.2\end{array}$ & $\begin{array}{l}5 \cdot 3 \\
5 \cdot 2 \\
5 \cdot 5\end{array}$ & $\begin{array}{l}0.4 \\
0.3 \\
0.1\end{array}$ & $\begin{array}{l}11 \cdot 9 \\
11 \cdot 8 \\
12 \cdot 1\end{array}$ & $\begin{array}{l}0.9 \\
0.7 \\
0.4\end{array}$ & $\begin{array}{l}3 \cdot 3 \\
3 \cdot 5 \\
3 \cdot 6\end{array}$ & $\begin{array}{l}0.1 \\
0.2 \\
0.2\end{array}$ & $\begin{array}{l}3 \cdot 0 \\
3 \cdot 4 \\
3 \cdot 3\end{array}$ & $\begin{array}{l}0.1 \\
0.2 \\
0.2\end{array}$ & $\begin{array}{l}5 \cdot 2 \\
5 \cdot 4 \\
5 \cdot 2\end{array}$ & $\begin{array}{l}0.1 \\
0 \cdot 2 \\
0.2\end{array}$ & $\begin{array}{l}11 \cdot 5 \\
12 \cdot 2 \\
12 \cdot 1\end{array}$ & $\begin{array}{l}0.3 \\
0.4 \\
0.4\end{array}$ \\
\hline Income & & & & & & & & & & & & & & & & \\
\hline $\begin{array}{l}<\text { \$US } 14999 \\
\text { \$US 15 000-24 999 } \\
\text { \$US 25 000-34 999 } \\
\text { \$US 35 000-79 999 } \\
\text { Don't know or didn't respond }\end{array}$ & $\begin{array}{l}3 \cdot 3 \\
3 \cdot 4 \\
3 \cdot 0 \\
3 \cdot 8 \\
4 \cdot 2\end{array}$ & $\begin{array}{l}0.2 \\
0.4 \\
0.3 \\
0.2 \\
1.0\end{array}$ & $\begin{array}{l}3 \cdot 3 \\
3 \cdot 0 \\
2 \cdot 7 \\
3 \cdot 6 \\
2 \cdot 4\end{array}$ & $\begin{array}{l}0.2 \\
0.4 \\
0.3 \\
0.2 \\
1.0\end{array}$ & $\begin{array}{l}5 \cdot 1 \\
5 \cdot 7 \\
5 \cdot 4 \\
5 \cdot 5 \\
7 \cdot 0\end{array}$ & $\begin{array}{l}0.2 \\
0.3 \\
0.3 \\
0.2 \\
0.9\end{array}$ & $\begin{array}{l}11 \cdot 6 \\
12 \cdot 1 \\
11 \cdot 1 \\
13 \cdot 0 \\
13 \cdot 6\end{array}$ & $\begin{array}{l}0.5 \\
0.8 \\
0.6 \\
0.5 \\
2.2\end{array}$ & $\begin{array}{l}3 \cdot 5 \\
3 \cdot 3 \\
3 \cdot 0 \\
3 \cdot 4 \\
3 \cdot 6\end{array}$ & $\begin{array}{l}0.1 \\
0.2 \\
0.2 \\
0.4 \\
0.2\end{array}$ & $\begin{array}{l}3 \cdot 3 \\
3 \cdot 1 \\
2 \cdot 9 \\
3 \cdot 2 \\
3 \cdot 2\end{array}$ & $\begin{array}{l}0.2 \\
0.2 \\
0.2 \\
0.4 \\
0.2\end{array}$ & $\begin{array}{l}5 \cdot 2 \\
5 \cdot 0 \\
5 \cdot 4 \\
5 \cdot 2 \\
5 \cdot 6\end{array}$ & $\begin{array}{l}0 \cdot 1 \\
0 \cdot 1 \\
0 \cdot 2 \\
0.4 \\
0 \cdot 2\end{array}$ & $\begin{array}{l}12 \cdot 1 \\
11.4 \\
11 \cdot 3 \\
11 \cdot 8 \\
12.5\end{array}$ & $\begin{array}{l}0.3 \\
0.3 \\
0.5 \\
0.9 \\
0.4\end{array}$ \\
\hline SNAP & & & & & & & & & & & & & & & & \\
\hline $\begin{array}{l}\text { No } \\
\text { Yes }\end{array}$ & $\begin{array}{l}3 \cdot 5 \\
3 \cdot 3\end{array}$ & $\begin{array}{l}0.2 \\
0.2\end{array}$ & $\begin{array}{l}3.4 \\
3.0\end{array}$ & $\begin{array}{l}0.2 \\
0.2\end{array}$ & $\begin{array}{l}5 \cdot 5 \\
5 \cdot 4\end{array}$ & $\begin{array}{l}0.2 \\
0.2\end{array}$ & $\begin{array}{l}12 \cdot 3 \\
11 \cdot 7\end{array}$ & $\begin{array}{l}0.4 \\
0.4\end{array}$ & $\begin{array}{l}3.6 \\
3.3\end{array}$ & $\begin{array}{l}0.1 \\
0.1\end{array}$ & $\begin{array}{l}3.4 \\
3.1\end{array}$ & $\begin{array}{l}0.1 \\
0.1\end{array}$ & $\begin{array}{l}5 \cdot 2 \\
5 \cdot 3\end{array}$ & $\begin{array}{l}0.1 \\
0.1\end{array}$ & $\begin{array}{l}12.2 \\
11.6\end{array}$ & $\begin{array}{l}0.3 \\
0.2\end{array}$ \\
\hline WIC & & & & & & & & & & & & & & & & \\
\hline No & 3.4 & 0.2 & $3 \cdot 1$ & 0.2 & $5 \cdot 6$ & 0.2 & $12 \cdot 1$ & 0.4 & $3 \cdot 2$ & 0.2 & $3 \cdot 1$ & 0.2 & $5 \cdot 3$ & 0.1 & 11.6 & 0.4 \\
\hline $\begin{array}{c}\text { Yes } \\
\text { Parent }\end{array}$ & 3.4 & 0.2 & 3.3 & 0.2 & $5 \cdot 3$ & 0.2 & $12 \cdot 0$ & 0.4 & 3.4 & 0.1 & $3 \cdot 2$ & 0.1 & $5 \cdot 2$ & 0.1 & 11.9 & 0.2 \\
\hline Full-time & $2 \cdot 6$ & 0.2 & $2 \cdot 4$ & 0.2 & $5 \cdot 3$ & 0.2 & $10 \cdot 3$ & 0.5 & $2 \cdot 7$ & 0.2 & $2 \cdot 3$ & 0.2 & $5 \cdot 2$ & 0.2 & $10 \cdot 2$ & 0.4 \\
\hline Part-time & 4.4 & 0.3 & 3.7 & 0.3 & 5.5 & 0.2 & $13 \cdot 6$ & 0.6 & $3 \cdot 3$ & 0.2 & 3.0 & 0.2 & $4 \cdot 8$ & 0.2 & $11 \cdot 1$ & 0.4 \\
\hline Not workin & 3.6 & 0.2 & 3.7 & 0.2 & $5 \cdot 4$ & 0.2 & $12 \cdot 6$ & 0.5 & 3.6 & 0.1 & 3.5 & 0.1 & 5.5 & 0.1 & $12 \cdot 6$ & 0.2 \\
\hline Adult bo & & & & & & & & & & & & & & & & \\
\hline $\begin{array}{l}\text { No } \\
\text { Yes }\end{array}$ & $\begin{array}{l}3.3 \\
3.5\end{array}$ & $\begin{array}{l}0.3 \\
0.2\end{array}$ & $\begin{array}{l}3 \cdot 3 \\
3 \cdot 1\end{array}$ & $\begin{array}{l}0.3 \\
0.2\end{array}$ & $\begin{array}{l}5 \cdot 1 \\
5.5\end{array}$ & $\begin{array}{l}0.2 \\
0.1\end{array}$ & $\begin{array}{l}11 \cdot 7 \\
12 \cdot 1\end{array}$ & $\begin{array}{l}0.6 \\
0.3\end{array}$ & $\begin{array}{l}3.4 \\
3 \cdot 1\end{array}$ & $\begin{array}{l}0.1 \\
0.3\end{array}$ & $\begin{array}{l}3.2 \\
3.1\end{array}$ & $\begin{array}{l}0.1 \\
0.3\end{array}$ & $\begin{array}{l}5 \cdot 2 \\
5 \cdot 7\end{array}$ & $\begin{array}{l}0.1 \\
0.3\end{array}$ & $\begin{array}{l}11.8 \\
11.9\end{array}$ & $\begin{array}{l}0.2 \\
0.7\end{array}$ \\
\hline
\end{tabular}

NET-Works, Now Everybody Together for Amazing and Healthy Kids; GROW, Growing Right Onto Wellness; SNAP, Supplemental Nutrition Assistance Program; WIC, Special Supplemental Nutrition Program for Women, Infants, and Children.

Greyed cells indicate significance after Bonferroni correction $(P<0.00143$ for non-Hispanics and $P<0.00161$ for Hispanics).

may be that the study did not measure the concept of merienda, which is a light meal eaten multiple times throughout the day. This concept is common in Latin American families. Thus, if Hispanic pre-school children were eating multiple types of meals per day it may have resulted in systematic measurement error that resulted in null findings for this group.
Furthermore, there were no significant associations found between family meal frequency by meal type and child BMI percentile for non-Hispanic or Hispanic pre-school children. This finding supports prior research conducted with elementary-school-aged children and adolescents that shows mixed findings regarding family meal frequency and child weight status ${ }^{(2,18,25,26,38-43)}$. One potential reason for this 
Table 3 Associations between family meal type (breakfast, lunch, dinner, total meals) and pre-school children's diet quality and BMI percentile among non-Hispanic and Hispanic households; baseline data from NET-Works and GROW studies among parent-child (aged 2-5 years) pairs from respectively Minnesota ( $n 222$ non-Hispanics; $n 312$ Hispanics) and Tennessee ( $n 545$ Hispanics; $n 55$ non-Hispanics), USA, 2012-2014

\begin{tabular}{|c|c|c|c|c|c|c|}
\hline & \multicolumn{2}{|c|}{$\begin{array}{l}\text { Non-Hispanic households } \\
\text { ( }(\text { 276) }\end{array}$} & \multirow[b]{2}{*}{$P$ value } & \multicolumn{2}{|c|}{$\begin{array}{l}\text { Hispanic households } \\
\text { ( }(n \text { 857) }\end{array}$} & \multirow[b]{2}{*}{$P$ value } \\
\hline & $\beta$ & SD & & $\beta$ & SD & \\
\hline \multicolumn{7}{|l|}{ HEI-2010 } \\
\hline \multicolumn{7}{|l|}{ Breakfast } \\
\hline Model $1^{*}$ & $1 \cdot 44$ & 0.32 & $<0.0001$ & $0 \cdot 19$ & 0.15 & 0.1899 \\
\hline Model $2 \dagger$ & $1 \cdot 10$ & 0.34 & 0.0013 & 0.15 & 0.15 & 0.3347 \\
\hline Model 3‡ & $1 \cdot 30$ & 0.41 & 0.0015 & 0.05 & 0.19 & 0.7948 \\
\hline \multicolumn{7}{|l|}{ Lunch } \\
\hline Model 1 & 0.61 & 0.33 & 0.0632 & 0.20 & 0.15 & 0.1799 \\
\hline Model 2 & 0.32 & 0.34 & 0.3345 & 0.13 & 0.15 & 0.3807 \\
\hline Model 3 & -0.46 & 0.40 & 0.2515 & 0.04 & 0.19 & 0.8497 \\
\hline \multicolumn{7}{|l|}{ Dinner } \\
\hline Model 1 & 0.50 & 0.39 & 0.1901 & 0.29 & 0.16 & 0.0728 \\
\hline Model 2 & 0.51 & 0.37 & 0.1721 & 0.29 & 0.16 & 0.0726 \\
\hline Model 3 & 0.37 & 0.38 & 0.3373 & 0.26 & 0.17 & 0.1204 \\
\hline \multicolumn{7}{|l|}{ Total } \\
\hline Model 1 & 0.52 & 0.15 & 0.0005 & 0.12 & 0.06 & 0.0578 \\
\hline Model 2 & 0.38 & $0 \cdot 15$ & 0.0137 & $0 \cdot 10$ & 0.07 & 0.1211 \\
\hline Model 3 & - & - & - & - & - & - \\
\hline \multicolumn{7}{|l|}{ BMI percentile } \\
\hline \multicolumn{7}{|l|}{ Breakfast } \\
\hline Model 1 & -0.27 & 0.37 & 0.4638 & 0.00 & 0.18 & 0.9793 \\
\hline Model 2 & -0.19 & 0.40 & 0.6433 & -0.12 & 0.19 & 0.5173 \\
\hline Model 3 & 0.12 & 0.48 & 0.8089 & -0.26 & 0.24 & 0.2723 \\
\hline \multicolumn{7}{|l|}{ Lunch } \\
\hline Model 1 & -0.31 & 0.37 & 0.3948 & 0.13 & 0.18 & 0.4780 \\
\hline Model 2 & -0.47 & 0.39 & 0.2293 & 0.06 & 0.19 & 0.7299 \\
\hline Model 3 & -0.54 & 0.47 & 0.2580 & 0.23 & 0.24 & 0.3453 \\
\hline \multicolumn{7}{|l|}{ Dinner } \\
\hline Model 1 & -0.26 & 0.43 & 0.5413 & -0.07 & 0.20 & 0.7326 \\
\hline Model 2 & -0.10 & 0.43 & 0.8193 & -0.01 & 0.20 & 0.9775 \\
\hline Model 3 & 0.04 & 0.45 & 0.9349 & 0.02 & 0.21 & 0.9413 \\
\hline \multicolumn{7}{|l|}{ Total } \\
\hline Model 1 & -0.17 & 0.17 & 0.3296 & 0.02 & 0.08 & 0.8502 \\
\hline Model 2 & -0.15 & 0.18 & 0.3903 & -0.01 & 0.08 & 0.8827 \\
\hline Model 3 & - & - & - & - & - & - \\
\hline
\end{tabular}

NET-Works, Now Everybody Together for Amazing and Healthy Kids; GROW, Growing Right Onto Wellness; SNAP, Supplemental Nutrition Assistance Program; WIC, Special Supplemental Nutrition Program for Women, Infants, and Children; HEI-2010, Health Eating Index-2010.

Estimates are beta coefficients. Interpretation = for every one-day increase in eating (breakfast, lunch, dinner, total) family meals, HEI-2010 score and BMI percentile changes. Values shown in bold are significant at $P<0.05$.

*Model 1: unadjusted.

†Model 2: adjusted for age, sex, marital status, employment status and site. For non-Hispanic participants, also adjusted for race/ethnicity. $\mathrm{BMI}$ models also adjusted for mean total daily energy intake.

¥Model 3: adjusted for all of the covariates in Model 2 plus the frequency of the other two family meals.

finding is that although the diet quality of foods consumed by children at family meals may be healthier (e.g. fruits, vegetables), the portion sizes of food consumed by children at family meals may still be large; thus, higher energy intake at family meals would not lead to lower weight status in children. Another reason may be that the weight status range in the samples was somewhat restricted, with one study having children between the 50th and 95th BMI percentile and the other study having all children at the 50th percentile or above.

There were several strengths and limitations of the study. Strengths of the study include the use of two large diverse samples from different parts of the USA with some common measures made possible through being part of a NIH-funded consortium; inclusion of a lower-income sample; detailed questions about family meal types; strong dietary intake assessment measures; and objectively measured child BMI. One limitation of the study was the inclusion of a restricted range of weight status, only including children from the 50th BMI percentiles and higher because these studies were obesity prevention trials. Another limitation is the cross-sectional nature of the baseline data, precluding the ability to examine temporal associations. An additional limitation was the use of singleitem questions assessing breakfast, lunch and dinner family meal frequencies. Furthermore, the family meal frequency questions were slightly different between NETWorks and GROW and it is possible that the different wording of the family meals frequency questions (i.e. 'How often did most of your family members eat...' $v$. 'How often did your family eat...') could explain some 
differences between groups. In addition, although $24 \mathrm{~h}$ dietary recalls are a stronger measure than self-report dietary intake, they still have inherent limitations such as day-to-day variability as well as larger errors for foods with higher energy density. Another limitation is that other important variables that could impact the association between family meals and diet quality, such as acculturation and parenting practices (e.g. parent feeding practices, parent modelling of healthy eating), were not assessed due to not having similar measures across the two sites. These measures would be important to include in future research.

\section{Implications for research and practice}

Results of the current study suggest that eating breakfast, lunch and dinner family meals was fairly common among non-Hispanic and Hispanic pre-school children. In addition, there were significant associations between frequency of breakfast and total weekly family meals and diet quality among non-Hispanic pre-school children, but not among Hispanic pre-school children. Findings from the current study may have implications for practice and research. While it appears that for non-Hispanic preschool children having breakfast and regular family meals across the week confers some dietary benefit, clinicians who work with families with pre-school children may want to be cautious in recommending the importance of having frequent breakfast, lunch or dinner family meals until more research can confirm or refute the current study findings. Specifically, longitudinal research is needed to understand more fully the association between the frequency of breakfast, lunch, dinner and total family meals and pre-school children's diet quality and weight status.

\section{Supplementary material}

To view supplementary material for this article, please visit https:/doi.org/10.1017/S1368980017002348

\section{Acknowledgements}

Financial support: This research was supported by grant number U01HD068990 (S.A.F and N.E.S. co-principal investigators; ClinicalTrials.gov identifier: NCT01606891), with additional support from other members of the Childhood Obesity Prevention and Treatment Research (COPTR) Consortium (grant numbers U01HL103622, U01HL103629, U01HL103620 and U01HL103561) supported by the National Heart, Lung, and Blood Institute (NHLBI), the Eunice Kennedy Shriver National Institute of Child Health and Development (NICHD), and the Office of Behavioral and Social Sciences Research, National Institutes of Health (NIH). J.M.B.'s time was supported by an $\mathrm{R} 56$ grant from the NHLBI (number HL116403). W.J.H.'s time was supported by a K12 grant from the Agency for Healthcare Research and Quality (number 1K12HS022990). Additionally, REDCap data collection was used, supported by grant number UL1TR000114 from the National Center for Advancing Translational Sciences (NCATS) and dietary data collected at Vanderbilt University was supported by grant number DK56350 from the National Institute of Diabetes and Digestive and Kidney Diseases (NIDDK). The content is solely the responsibility of the authors and does not necessarily represent the official views of the NHLBI, the NICHD, the Office of Behavioral and Social Sciences Research or the NIH. Conflict of interest: Authors have no conflicts of interest to report. Authorship: All co-authors made a substantial contribution to the paper as described below and agree to be accountable for all aspects of the work regarding the accuracy or integrity of any part of the work. J.M.B. conceptualized the paper, assisted with data analysis and interpretation, wrote all drafts of the paper, and gave final approval of this version to be published. K.P.T. conducted the data analysis, critically reviewed the paper, and gave final approval of this version to be published. N.E.S. is a co-principal investigator on the NET-Works grant, she assisted with data interpretation, critically reviewed the paper, and gave final approval of this version to be published. N.M. assisted with data analysis and interpretation, critically reviewed the paper, and gave final approval of this version to be published. W.J.H. assisted with interpretation of the data, critically reviewed the paper, and gave final approval of this version to be published. S.B. is the principal investigator on the GROW grant, she critically reviewed the paper, and gave final approval of this version to be published. D.M. assisted with conceptualization of the paper, critically reviewed the paper, and gave final approval of this version to be published. C.E.L.-L. assisted with conceptualization of the paper, she critically reviewed the paper, and gave final approval of this version to be published. S.A.F. is a co-principal investigator on the NET-Works grant, she critically reviewed the paper, and gave final approval of this version to be published. Ethics of human subject participation: The IRB Human Subjects Committee at the University of Minnesota and Vanderbilt University approved all protocols used in the NET-Works and GROW study, respectively. All participants signed written informed consent prior to participation into the respective studies. Additionally, the University of North Carolina at Chapel Hill IRB, which is the coordinating centre for the COPTR Consortium, approved the analysis of the data from both studies.

\section{References}

1. Berge JM, Wall M, Hsueh TF et al. (2015) The protective role of family meals for youth obesity: 10-year longitudinal associations. J Pediatr 166, 296-301.

2. Fulkerson JA, Neumark-Sztainer D, Hannan PJ et al. (2008) Family meal frequency and weight status among adolescents: cross-sectional and 5-year longitudinal associations. Obesity (Silver Spring) 16, 2529-2534.

3. Larson N, MacLehose R, Fulkerson JA et al. (2013) Eating breakfast and dinner together as a family: associations with sociodemographic characteristics and implications for diet quality and weight status. J Acad Nutr Diet 113, 1601-1609. 
4. Larson NI, Neumark-Sztainer D, Hannan PJ et al. (2007) Family meals during adolescence are associated with higher food quality and healthful meal patterns during young adulthood. J Am Diet Assoc 107, 1502-1510.

5. Neumark-Sztainer D, Story M, Ackard D et al. (2000) Family meals among adolescents: findings from a pilot study. J Nutr Educ 32, 335-340.

6. Goldfield GS, Murray MA, Buchholz A et al. (2011) Family meals and body mass index among adolescents: effects of gender. Appl Physiol Nutr Metab 36, 539-546.

7. Chan JC \& Sobal J (2011) Family meals and body weight. Analysis of multiple family members in family units. Appetite 57, 517-524.

8. Christian MS, Evans CEL, Hancock N et al. (2013) Family meals can help children reach their 5 A Day: a cross-sectional survey of children's dietary intake from London primary schools. J Epidemiol Community Health 67, 332-338.

9. Utter J, Denny S, Robinson E et al. (2013) Family meals and the well-being of adolescents. J Paediatr Child Health 49, 906-911.

10. Woodruff SJ, Hanning RM, McGoldrick K et al. (2010) Healthy Eating Index-C is positively associated with family dinner frequency among students in grades 6-8 from Southern Ontario, Canada. Eur J Clin Nutr 64, 454-460.

11. Leech RM, Worsley A, Timperio A et al. (2015) Understanding meal patterns: definitions, methodology and impact on nutrient intake and diet quality. Nutr Res Rev 28, 1-21.

12. McCullough MB, Robson SM \& Stark LJ (2016) A review of the structural characteristics of family meals with children in the United States. Adv Nutr 7, 627-640.

13. Andaya AA, Arredondo EM, Alcaraz JE et al. (2011) The association between family meals, TV viewing during meals, and fruit, vegetables, soda, and chips intake among Latino children. J Nutr Educ Behav 43, 308-315.

14. Valdes J, Rodriguez-Artalejo F, Aguilar L et al. (2013) Frequency of family meals and childhood overweight: a systematic review. Pediatr Obes 8, e1-e13.

15. Burgess-Champoux TL, Larson N, Neumark-Sztainer D et al. (2009) Are family meal patterns associated with overall diet quality during the transition from early to middle adolescence? J Nutr Educ Behav 41, 79-86.

16. Larson NI, Nelson MC, Neumark-Sztainer D et al. (2009) Making time for meals: meal structure and association with dietary intake in young adults. J Am Diet Assoc 109, 72-79.

17. Larson NI, Neumark-Sztainer D, Harnack L et al. (2008) Fruit and vegetable intake correlates during the transition to young adulthood. Am J Prev Med 35, 33-37.

18. Fulkerson JA, Kubik MY, Story M et al. (2009) Are there nutritional and other benefits associated with family meals among at-risk youth? J Adolesc Health 45, 389-395.

19. Fulkerson JA, Rydell S, Kubik MY et al. (2010) Healthy Home Offerings via the Mealtime Environment (HOME): feasibility, acceptability, and outcomes of a pilot study. Obesity (Silver Spring) 18, Suppl. 1, S69-S74.

20. Fruh SM, Fulkerson JA, Mulekar MS et al. (2011) The surprising benefits of the family meal. J Nurse Pract 7 , $18-22$.

21. Hammons AJ \& Fiese BH (2011) Is frequency of shared family meals related to the nutritional health of children and adolescents? Pediatrics 127, e1565-e1574.

22. Blondin SA, Anzman-Frasca S, Djang HC et al. (2016) Breakfast consumption and adiposity among children and adolescents: an updated review of the literature. Pediatr Obes 11, 333-348.

23. Larson N, Wang Q, Berge JM et al. (2016) Eating breakfast together as a family: mealtime experiences and associations with dietary intake among adolescents in rural Minnesota, USA. Public Health Nutr 19, 1565-1574.

24. Larson NI, Miller JM, Watts AW et al. (2016) Adolescent snacking behaviors are associated with dietary intake and weight status. J Nutr 146, 1348-1355.
25. Fulkerson JA, Larson N, Horning M et al. (2014) A review of associations between family or shared meal frequency and dietary and weight status outcomes across the lifespan. J Nutr Educ Behav 46, 2-19.

26. Rollins BY, Belue RZ \& Francis LA (2010) The beneficial effect of family meals on obesity differs by race, sex, and household education: the national survey of children's health, 2003-2004. J Am Diet Assoc 110, 1335-1339.

27. Fulkerson JA, Pasch KE, Stigler MH et al. (2010) Longitudinal associations between family dinner and adolescent perceptions of parent-child communication among racially diverse urban youth. J Fam Psychol 24, 261-270.

28. Sherwood NE, French SA, Veblen-Mortenson S et al. (2013) NET-Works: linking families, communities and primary care to prevent obesity in preschool-age children. Contemp Clin Trials 36, 544-554.

29. Po'e EK, Heerman WJ, Mistry RS et al. (2013) Growing Right on to Wellness (GROW): a family-centered, community-based obesity prevention randomized controlled trial for preschool child-parent pairs. Contemp Clin Trials 36, 436-449.

30. Kuczmarski RJ, Ogden CL, Grummer-Strawn LM et al. (2000) CDC growth charts: United States. Adv Data issue 314, 1-27.

31. Neumark-Sztainer D, Larson NI, Fulkerson JA et al. (2010) Family meals and adolescents: what have we learned from Project EAT (Eating Among Teens)? Public Health Nutr 13, $1113-1121$.

32. Centers for Disease Control and Prevention, National Center for Health Statistics (2000) CDC Growth Charts: United States. http://www.cdc.gov/growthcharts/ (accessed January 2017).

33. Guenther PM, Casavale KO, Reedy J et al. (2013) Update of the Healthy Eating Index: HEI-2010. J Acad Nutr Diet 113, 569-580.

34. Guenther PM, Kirkpatrick SI, Reedy J et al. (2014) The Healthy Eating Index-2010 is a valid and reliable measure of diet quality according to the 2010 Dietary Guidelines for Americans. J Nutr 144, 399-407.

35. Pourhoseingholi M, Baghestani A \& Vahedi M (2012) How to control confounding effects by statistical analysis. Gastroenterol Hepatol 5, 79-83.

36. Neumark-Sztainer D, Hannan PJ, Story M et al. (2003) Family meal patterns: associations with sociodemographic characteristics and improved dietary intake among adolescents. J Am Diet Assoc 103, 317-322.

37. Larson N, Fulkerson J, Story M et al. (2013) Shared meals among young adults are associated with better diet quality and predicted by family meal patterns during adolescence. Public Health Nutr 16, 883-893.

38. Wurbach A, Zellner K \& Kromeyer-Hauschild K (2009) Meal patterns among children and adolescents and their associations with weight status and parental characteristics. Public Health Nutr 12, 1115-1121.

39. Utter J, Denny S, Robinson E et al. (2013) Family meals among New Zealand young people: relationships with eating behaviors and body mass index. J Nutr Educ Behav 45, 3-11.

40. Veltsista A, Laitinen J, Sovio U et al. (2010) Relationship between eating behavior, breakfast consumption, and obesity among Finish and Greek adolescents. J Nutr Educ Behav 42, 417-421.

41. Berge JM (2009) A review of familial correlates of child and adolescent obesity: what has the 21st century taught us so far? Int J Adolesc Med Health 21, 457-483.

42. Berge JM, Jin SW, Hannan P et al. (2013) Structural and interpersonal characteristics of family meals: associations with adolescent body mass index and dietary patterns. J Acad Nutr Diet 113, 816-822.

43. Berge JM, Rowley S, Trofholz A et al. (2014) Childhood obesity and interpersonal dynamics during family meals. Pediatrics 134, 923-932. 